\title{
НОВЫЕ АСПЕКТЫ БИОЛОГИЧЕСКОЙ РОЛИ СИСТЕМНОЙ И ЛОКАЛЬНОЙ ГИПЕРПРОЛАКТИНЕМИИ
}

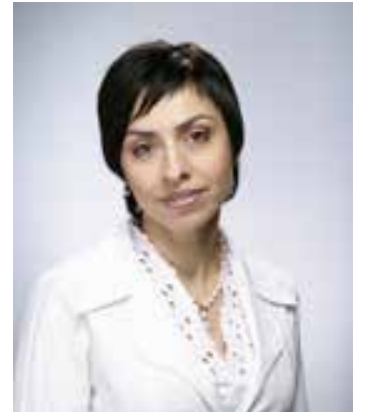

H.В. КОСЕЙ

д.мед.н., главный научный сотрудник отделения эндокринной гинекологии Института педиатрии, акушерства и гинекологии НАМН Украины

\section{Т.Н. ТУТЧЕНКО} к.мед.н., научный сотрудник отделения эндокринной гинекологии Института педиатрии, акушерства и гинекологии НАМН Украины

\section{Л.А. ВАСИЛЬЧЕНКО}

аспирант отделения эндокринной гинекологии Института педиатрии, акушерства и гинекологии НАМН Украины
$\mathrm{H}_{\mathrm{cos}}^{\mathrm{e}}$ есмотря на значительную эфффективность современных хирургических методов лечения доброкачественных опухолей матки и молочных желез, вопрос профилактики их рецидивного роста остается черезвычайно актуальным, что диктует необходимость продолжения углубленных исследований патогенеза гиперпролиферативных процессов репродуктивных органов женщины.

Небезосновательно в течение последнего времени повышенное внимание ученых было направлено на пересмотр биологической роли пролактина - пептида преимущественно гипофизарного происхождения - на протяжении многих лет рассматривавшегося в достаточно узких рамках обеспечения лактогенеза (лактопоэза) и участия в процессах репродукции [1-3]. Известно, что пролактин участвует в регуляции гипоталамо-гипофизарно-гонадотропной оси: влияет на секрецию гонадотропных рилизинг-гормонов и частоту импульсов лютеинизирующего гормона, а соответственно, и на рост и созревание фолликулов, овуляцию, функцию желтого тела. Во время беременности фризиологические концентрации пролактина поддерживают активность желтого тела и выработку прогестерона, стимулируют рост и развитие молочных желез и образование молока [4-6].

Исследования в области нейрофизиологии осветили другую грань биологической роли пролактина - роли нейромедиатора. Установлена критическая значимость физиологических уровней этого гормона в формировании либидо, пищевого, полового и родительского поведения; обеспечении полноценного процесса сна за счет фразы быстрого сна; обмене других нейротрансмиттеров ( $\gamma$-аминомасляной кислоты, опиоидов, ацетилхолина, серотонина); работе $\mathrm{Ca}^{2+}$ и K'-каналов [1-3].

Раскрытие патогенеза стресс-индуцированной патологии показало, что наряду с надпочечниковыми гормонами пролактин является одним из наиболее активных участников энергетического и пластического обеспечения стресс-реакции: способен повышать содержание ДНК и РНК, ускорять синтез белка в клетке, повышать активность фоссратаз, увеличивать количество гликогена в клетках, уменьшать потребление глюкозы и кислорода, в целом активируя анаболические процессы в организме [5, 6, 8-10]. Вышеперечисленные механизмы имеют важное значение в адаптации организма к экстремальным условиям.
Описанное разнообразие функций пролактина обусловливает, во-первых, значительную вариабельность его концентраций в системном кровотоке в зависимости от условий существования индивида, во-вторых, наличие его рецепторов в большинстве органов и тканей. Эти же факторы подтолкнули ученых к рассмотрению пролактина в роли фрактора туморогенеза [10-13].

Когортные исследования 90-х годов прошлого века продемонстрировали, что повышенные в пределах нормы уровни циркулирующего в крови пролактина являются фрактором риска развития рака молочной железы и простаты, однако патогенез этого явления долгое время не мог быть полностью объяснен теоретически и воспроизведен в лабораторных моделях $[10,11]$.

В ходе современных исследований в этом направлении была установлена двойственная природа пролактина: с одной стороны, он является гипофизарным гормоном, регуляция секреции которого осуществляется преимущественно с участием дофамина, а с другой - проявляет свойства цитокина, реализуя свои эфффекты в пределах тканей за счет пара- и аутокринных механизмов регуляции, большинство из которых до конца не раскрыто. Существуют предположения о разностороннем активирующем/супрессирующем (up-regulation/downregulation) взаимодействии гипофизарного пролактина и его тканевого аналога посредством различных промежуточных субстанций $[1,13]$. На сегодняшний день промежуточные результаты текущих молекулярно-биологических исследований роли пролактина в туморогенезе указывают на то, что ведущую роль в патогенезе как доброкачественных гиперпролиферативных, так и злокачественных процессов играют количество и функциональная активность рецепторов пролактина $[1,14]$. Измененная активность рецепторов пролактина в большинстве случаев обусловлена точечными генетическими мутациями, что создает значительные технические сложности в исследовании этого вопроса и требует больших временных затрат [1, 14].

Пролактин-рецепторные системы были выявлены во многих органах и тканях, в т.ч. в ткани мио-, эндометрия и лейомиомы матки (ЛМ) [15-17]. R. Nowak et al. в своих исследованиях показали, что пролактин выступает в роли митогенного фрактора роста для ткани ЛМ и клеток миометрия [18]. Учитывая множественные фрормы и функции пролактина, 
можно предположить реализацию его эффректов с участием различных механизмов. Экспериментальным путем было выявлено, что пролактин стимулирует продукцию фракторов роста, в частности инсулиноподобного фактора роста 1, снижает в печени синтез глобулина, связывающего половые гормоны, способствуя повышению концентрации свободных половых стероидов; угнетает апоптоз, а также обладает способностью непосредственно стимулировать митотическую активность гладкомышечных клеток матки [15-19].

Установлено, что клетки миомы матки также секретируют пролактин. Поэтому роль этого гормона в патогенезе ЛМ и его влияние на рост опухоли находится в поле зрения многих современных исследователей. У человека пролактин кодируется единственным геном, экспрессирующимся в гипофизе. R. Nowak et al. (1993) обнаружили, что ЛМ секретирует пролактин, идентичный гипофизарному по иммунологическим и хроматографическим характеристикам. Эти клетки способны экспрессировать ген пролактина, причем его митохондриальная РНК в ткани ЛМ на 150 kb длиннее гипофизарной митохондриальной РНК за счет дополнительного некодирующего экзона. Исследования на культуре ткани показали, что для секреции пролактина эндометрием в фразе пролиферации необходимо присутствие прогестерона, тогда как добавление эстрадиола снижает его синтез. При исследовании культуры тканей ЛМ и здорового миометрия обработка нейтрализующим пролактин антителом угнетала пролиферацию клеток в обоих случаях, что свидетельствовало в пользу предположения о роли пролактина как фрактора роста для гладкомышечных клеток [20-24].

Интерес представляют недавно опубликованные работы, указывающие на эффрективность лечения ЛМ с уменьшением ее размеров на 50\% при применении каберголина, однако малое количество случаев в исследованиях пока не позволяет рекомендовать эту тактику к рутинному использованию [25-27].

Известно, что довольно часто миома сочетается с дисгормональными заболеваниями молочной и щитовидной желез, а нередко эта опухоль развивается изолированно, без сопутствующей патологии [6, 24, 28-30].

\section{ЦЕЛЬ, МАТЕРИАЛЫ}

\section{И МЕТОДЫ ИССЛЕДОВАНИЯ}

С целью изучения особенностей общего и локального содержания пролактина у 171 пациентки репродуктивного возраста (18-36 лет) с ЛМ было проведено изучение его концентрации в сыворотке крови кубитальной вены и смешанной артериовенозной крови сосудов матки, полученной во время проведения диагностического выскабливания ее полости.

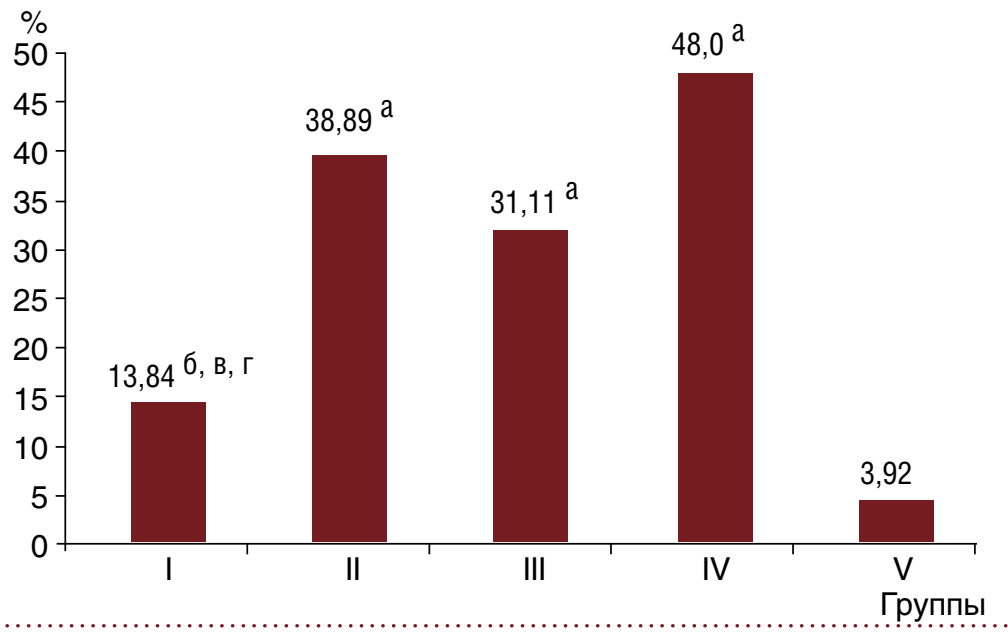

Группу контроля составила 51 здоровая женщина. В зависимости от наличия патологии молочной и щитовидной желез пациентки были разделены на группы: 65 женщин с изолированной ЛМ составили I группу, 36 пациенток с сочетанием ЛМ и дисгормональных заболеваний молочной железы (ДЗМЖ) - II группу, 45 женщин с сочетанной патологией матки и щитовидной железы - III группу, 25 пациенток с сочетанием ЛМ, ДЗМЗ и патологи щитовидной железы - IV группу. Во избежание колебаний концентрации гормона в зависимости от фразы менструального цикла у всех пациенток забор крови проводили во вторую фразу цикла.

Кроме того, у 31 пациентки, давшей согласие на пункцию бедренной вены и катетеризацию маточной вены, было проведено сравнение содержания пролактина в сыворотке крови кубитальной вены и маточных артерии и вены, полученной при ангиографии при проведении эмболизации маточных артерий. В этой группе 16 женщин имели изолированную форму ЛМ, 15 - сочетанную патологию матки, молочной и щитовидной желез.

\section{РЕЗУЛЬТАТЫ ИССЛЕДОВАНИЯ}

Анализ полученных результатов показал, что все варианты сочетанной ЛМ (группы II, III и IV) сопровождались более высокой частотой гиперпролактинемий в центральном кровотоке (по данным его концентрации в кубитальной вене) по сравнению с показателями при изолированном росте опухоли и у здоровых женщин (рис. 1).

Это было обусловлено повышением концентрации гормона у 38,89\% женщин II группы до 26,0-97,4 нг/мл; у 31,11\% женщин III группы до 25,4-68,6 нг/мл; у 48,0\% пациенток IV группы до 26,1-103,6 нг/мл. Следует отметить, что у большинства женщин с гиперпролактинемией в центральном кровотоке уровни пролактина были повышены незначительно - до 28-50 нг/мл, и лишь в единичных случаях цифры были выше. Такой уровень гиперпролактинемии чаще указывает на функциональный
РИС. 1. УДЕЛЬНЫЙ ВЕС ПАЦИЕНТОК С ГИПЕРПРОЛАКТИНЕМИЕЙ В ЦЕНТРАЛЬНОМ КРОВОТОКЕ В ОБСЛЕДОВАННЫХ ГРУППАХ

а - разница достоверна относительно показателя V (контрольной) группы $(p<0,05)$; б - разница достоверна относительно показателя IV группы $(p<0,05)$; в - разница достоверна относительно показателя III группы $(p<0,05)$;

$г$ - разница достоверна относительно показателя ॥ группы $(p<0,05)$ 
ТАБЛИЦА 1

\begin{tabular}{|c|c|c|c|}
\hline \multirow[b]{2}{*}{ Группа женщин } & \multirow[b]{2}{*}{$\mathrm{n}$} & \multicolumn{2}{|c|}{ Концентрация пролактина, нг/мл } \\
\hline & & Кровь кубитальной вены & $\begin{array}{c}\text { Смешанная кровь сосудов } \\
\text { матки }\end{array}$ \\
\hline I & 65 & $15,41 \pm 2,3^{\ulcorner, 6}$ & $38,63 \pm 3,56$ а,б,в,г,Д \\
\hline ॥ & 36 & $24,77 \pm 1,25^{a}$ & $17,49 \pm 2,81$ \\
\hline III & 45 & $20,90 \pm 0,98$ б,a & $19,72 \pm 1,96$ \\
\hline IV & 25 & $28,36 \pm 1,36^{\mathrm{B}, \mathrm{a}, \mathrm{6}}$ & $22,38 \pm 2,57^{\mathrm{a}}$ \\
\hline V & 51 & $14,63 \pm 1,55$ & - \\
\hline
\end{tabular}

ТАБЛИЦА 1.

СРЕДНИЕ ПОКАЗАТЕЛИ

КОНЦЕНТРАЦИИ ПРОЛАКТИНА В ОБЩЕМ И ЛОКАЛЬНОМ КРОВОТОКЕ В ОБСЛЕДОВАННЫХ ГРУППАХ ЖЕНЩИН, $\mathrm{M} \pm \mathrm{m}$

а - разница достоверна относительно показателя в

$\mathrm{V}$ группе $(p<0,05)$;

б - разница достоверна

относительно показателя в

IV группе ( $<$ 0,05);

в - разница достоверна

относительно показателя в

III группе $(p<0,05)$;

г - разница достоверна

относительно показателя во

II группе $(p<0,05)$;

д - разница достоверна

относительно показателей в кубитальной вене $(p<0,05)$

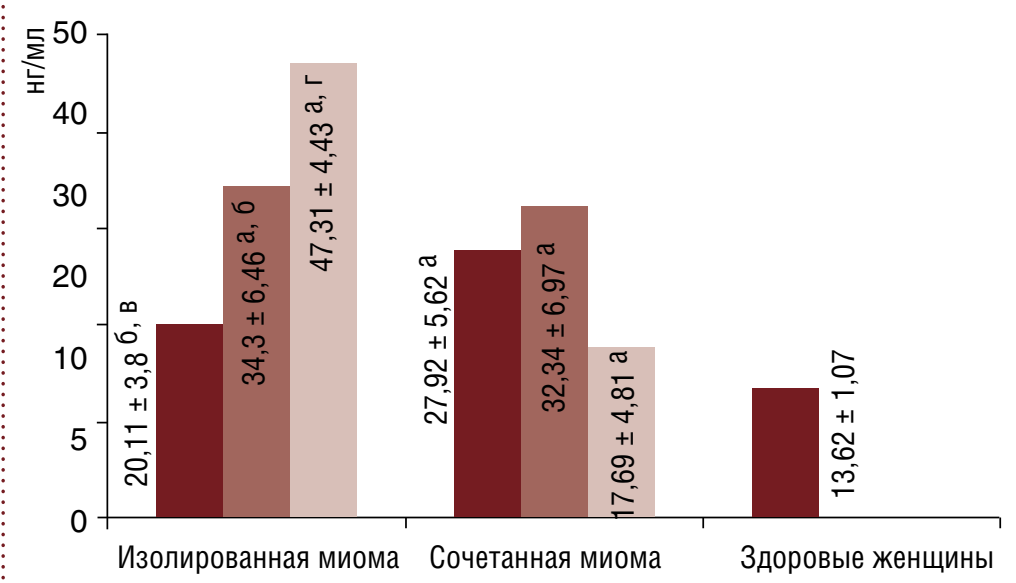

— Кубитальная вена

РИС. 2.

СРЕДНИЕ ПОКАЗАТЕЛИ

КОНЦЕНТРАЦИЙ ПРОЛАКТИНА

В СЫВОРОТКЕ КРОВИ

КУБИТАЛЬНОЙ ВЕНЫ,

МАТОЧНЫХ АРТЕРИИ И ВЕНЫ

У ЖЕНЩИН С ЛМ, $\mathrm{M} \pm \mathrm{m}$

а - разница достоверна

относительно показателя в

контрольной группе $(p<0,05)$;

б - разница достоверна

относительно показателей в

a. uterina в пределах

группы $(p<0,05)$;

в - разница достоверна

относительно показателей в

v. uterina в пределах

группы $(p<0,05)$;

г- разница достоверна

относительно показателей

при сочетанной ЛМ $(p<0,05)$ a. uterina

v. uterina

характер нарушений, в частности на фоне стресса, фризического переутомления, нарушения режима сна и бодрствования. Из этого можно сделать предположение, что пролиферативный эффект пролактина более выражен при умеренном повышении его концентрации, в то время как пациентки с уровнями гиперпролактинемии, в 3-4 раза превышающими норму, чаще страдали угнетением стероидпродуцирующей функции и отсутствием менструального цикла наряду с проявлениями гипоэстрогении.

Больший удельный вес гиперпролактинемий в случаях сочетанной гиперпролиферативной патологии сопровождался существенно более высокими концентрациями пролактина в сыворотке крови кубитальной вены в сравнении с данными у здоровых женщин (V группа) и

$$
\text { су }
$$
сак, средние показатели содержания пролактина в сыворотке крови сосудов матки (артерии 34,3 \pm 6,46 нг/мл, вены 47,31 + 4,43 нг/мл) значительно превышали таковые в крови кубитальной вены $\left(20,11 \pm 3,8\right.$ нг/мл, $\left.p_{1-3,2-3}<0,05\right)$, что подтверждает предположение о значении локальной гиперпролактинемии в механизме развития этой доброкачественной опухоли матки в случаях изолированного варианта ее развития (рис. 2). В a. uterina этот показатель был выше в 1,7 раза, а в v. uterina - в 2,37 раза, чем в кубитальной вене. При этом в сыворотке крови v. uterina средняя концентрация пролактина $(47,31 \pm 4,43$ нг/мл) превышала таковую в маточной артерии (34,3 \pm 6,46 нг/мл, $р<0,05)$. Индивидуальный анализ уровней пролактина показал, что в 10 (62,5\%) случаях изолированного роста ЛМ в венозной крови этот показатель был выше, чем в артериальной крови, в 2 (12,5\%) - не отличался, а в 4 (25,0\%) случаях был ниже, чем в притекающей к матке крови. Описанные изменения дают основания предположить наличие локальной продукции пролактина в ткани ЛМ или нарушение его оттока от матки.

В отличие от изолированного сочетанный клинический вариант заболевания характеризовался достаточно близкими средними величинами концентраций гормона во всех трех образцах крови, превышавшими показатели здоровых женщин. На фоне отсутствия 


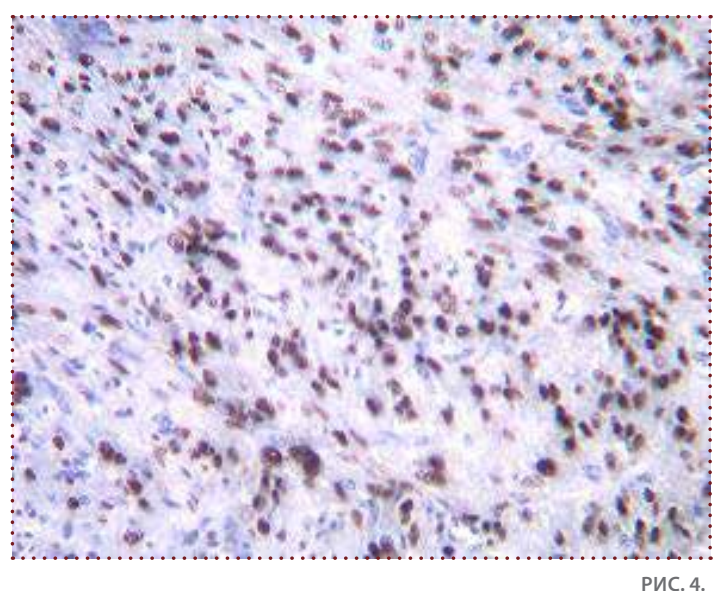

МИКРОФОТОГРАФИЯ. ЛМ ПАЦИЕНТКИ IV ГРУППЫ. ВЫСОКАЯ СТЕПЕНЬ (2-3 БАЛЛА) ЭКСПРЕССИИ РЕЦЕПТОРОВ К ПРОЛАКТИНУ В ЯДРАХ ГЛАДКОМЫШЕЧНЫХ КЛЕТОК. ИММУНОГИСТОХИМИЧЕСКАЯ РЕАКЦИЯ ЭКСПРЕССИИ РЕЦЕПТОРОВ К ПРОЛАКТИНУ НЕПРЯМЫМ СТРЕПТОВИДИН-ПЕРОКСИДАЗНЫМ МЕТОДОМ. ОК. 10. ОБ. 40

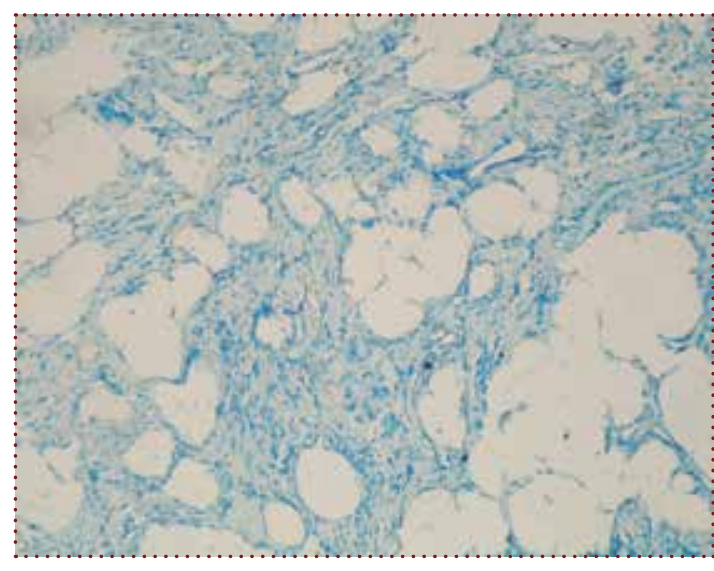

РИС. 5.

МИКРОФОТОГРАФИЯ. ЛМ ПАЦИЕНТКИІІГРУППЫ С ОЧАГАМИ ЛИПОЛЕЙОМИОМЫ. НЕГАТИВНАЯ РЕАКЦИЯ НА ПРОЛАКТИН. ИММУНОГИСТОХИМИЧЕСКАЯ РЕАКЦИЯ ЭКСПРЕССИИ РЕЦЕПТОРОВ К ПРОЛАКТИНУ НЕПРЯМЫМ СТРЕПТОВИДИН-ПЕРОКСИДАЗНЫМ МЕТОДОМ. ОК. 10. ОБ. 20

\begin{tabular}{|c|c|}
\hline Группа женщин & n \\
\hline I & 15 \\
\hline II & 1 \\
\hline III & 12 \\
\hline IV & 1 \\
\hline
\end{tabular}

\begin{tabular}{|c|c|}
\hline $\mathbf{n}$ & 0 баллов \\
\hline 15 & $11(73,33)^{\mathrm{a}}$ \\
\hline 14 & $5(35,71)^{6}$ \\
\hline 12 & $7(58,33)$ \\
\hline 14 & $3(21,43)$ \\
\hline
\end{tabular}

достоверных различий между артериальными и венозными показателями гормонального гомеостаза матки выявлена тенденция $(t=1,79) \mathrm{k}$ более высокому уровню пролактина в a. uterina в сравнении с таковым в v. uterina. Такая направленность различий между сыворотками артериальной и венозной крови матки выявлена у 11 (73,33\%) женщин с изолированной ЛМ, у 1 (6,67\%) пациентки показатели не отличались, а у 3 (20,0\%) - содержание пролактина в артериальной крови было ниже такового в вене матки. Это может указывать на значительное поступление пролактина из центрального кровотока в случаях сочетания дисгормональных процессов репродуктивной системы и щитовидной железы и существенное потребление его в миоматозной матке.

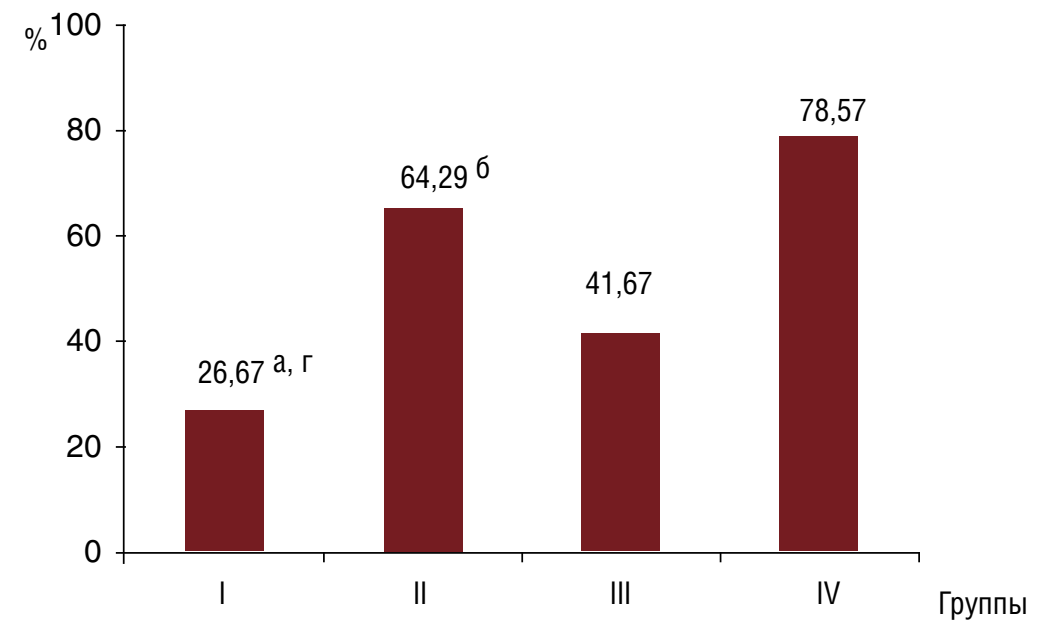

Внедрение иммуногистохимических методов в морфологических исследованиях значительно расширило возможности выявления некоторых звеньев патогенеза патологических процессов.

При оценке уровня экспрессии рецепторов к пролактину в зависимости от клинико-патогенетического варианта развития ЛМ выявили значительно более высокую частоту пролактинпозитивных ЛМ в случаях их сочетания с ДЗМЖ и заболеваний щитовидной железы (табл. 2). При этом отмечена высокая степень (2-3 балла) экспрессии рецепторов данного гормона, преимущественно в ядрах гладкомышечных клеток вокруг сосудов (рис. 3-5).

Полученные данные указывают на высокую чувствительность ЛМ к пролактину, особенно при сочетании ее с патологией молочных желез. Однако даже среди изолированно расту-

ТАБЛИЦА 2

Степень выраженности экспрессии рецепторов к пролактину

\begin{tabular}{|c|c|c|}
\hline $\mathbf{1}$ балл & $\mathbf{2}$ балла & $\mathbf{3}$ балла \\
\hline $3(20,0)$ & $1(6,67)$ & - \\
\hline $2(14,29)$ & $4(28,57)$ & $3(21,43)$ \\
\hline- & $3(25,0)$ & $2(16,67)$ \\
\hline $4(28,57)$ & $3(21,43)$ & $4(28,57)$ \\
\hline
\end{tabular}

щих ЛМ четверть оказалась пролактинположительной, что указывает на значительную роль данного гормона как паракринного фрактора роста опухоли.

\section{ОБСУЖДЕНИЕ}

Представленные данные свидельствуют о том, что общая и локальная гиперпролактинемия является одним из важных звеньев в механизме развития ЛМ. При этом центральная гиперпролактинемия играет более важную роль в росте сочетанной с патологией молочной и щитовидной желез ЛМ, в то время как в случаях изолированной патологии матки большее значение имеет местно синтезированный пролактин. О возможном повышении содержания данного пептида в локальном кровотоке ОПУХОЛЕЙ В ОБСЛЕДОВАННЫХ ГРУППАХ ЖЕНЩИН, АБС. ЧИСЛО (\%)

а - разница достоверна относительно показателя в IV группе $(p<0,05)$;

б - разница достоверна относительно показателя в

III группе $(p<0,05)$;

в - разница достоверна относительно показателя во II группе $(p<0,05)$ ПРОЛАКТИНПОЛОЖИТЕЛЬНЫХ

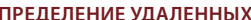
ОПУХОЛЕЙ ПО ИНТЕНСИВНОСТИ К ПРОЛАКТИНУ, АБС. ЧИСЛО (\%)

а - разница достоверна относительно показателя в IV группе $(\mathrm{p}<0,05)$;

$\sigma$ - разница достоверна относительно показателя в III группе $(p<0,05)$ ЭКСПРЕССИИ В НИХ РЕЦЕПТОРОВ 
следует помнить, получая нормальный результат обследования на пролактин у женщин с ЛМ.

Подбирая метод лечения ЛМ в зависимости от локализации и величины узлов, важно не забывать о необходимости коррекции состояний, являющихся причиной роста опухоли. Конечно, нормализация содержания пролактина не заменит традиционных методов лечения ЛМ и уже вряд ли скажется на величине опухоли - с этой целью придется применять запланированные методы лечения миомы (консервативную миомэктомию, гистероскопическую резекцию, эмболизацию маточных артерий и т.д.). Однако сохраняющиеся после удаления опухоли гормональные и иммунологические нарушения, лежащие в основе развития ЛМ, не только являются причиной высокой частоты рецидивирования опухоли (от 5 до 50\%), но и значительно ухудшают репродуктивные прогнозы после миомэктомии [27-29]. Поэтому планирование лечения опухоли любым из органосохраняющих методов должно включать углубленное исследование всех возможных этиологических фракторов на предоперационном этапе с целью проведения их своевременной коррекции. Кроме того, в случаях наличия ЛМ небольших размеров, когда основная цель лечения - стабилизация размеров опухоли и профилактика быстрого ее роста, большое значение имеет нормализация гормонального статуса. Учитывая результаты проведенных исследований, коррекцию гиперпролактинемии можно считать патогенетически обоснованной составляющей комплексного лечения ЛМ и профилактики ее роста.

В последние десятилетия для лечения эндокринных расстройств все шире применяются средства натурального (в частности растительного) происхождения. Особого внимания заслуживают фитопрепараты, оказывающие специфическое селективное рецептормодулирующее действие. Эти препараты можно считать средством выбора в начале терапии дисгормональных расстройств, в т.ч. гиперпролактинемии, имея в виду их безопасность и возможность назначения широкому кругу пациенток.

Поскольку в подавляющем большинстве случаев ЛМ имеет место умеренная гиперпролактинемия, чаще функционального характера, именно лекарственные средства растительного происхождения являются наиболее оптимальными и в большинстве случаев достаточно эффективными [28, 29]. Наиболее изученными и хорошо зарекомендовавшими себя с точки зрения лечения гиперпролактинемии являются Мастодинон и Циклодинон. Эти растительные препараты содержат специальный экстракт Vitex agnus castus (BNO 1095), стандартизованный по количественному содержанию BNO-детерпенов. Благодаря допаминергическому действию на лактотрофные клетки гипофриза BNO-детерпены в составе Мастодинона и Циклодинона угнетают патологически повышенную секрецию пролактина, что способствует нормализации функционирования гипоталамо-гипофизарно-яичниковой системы. Данные препараты изготавливаются путем фитониринга, что представляет собой замкнутый процесс производства от начала подготовки грунта и выращивания сортовых лекарственных растений до изготовления готовых форм препаратов. Именно такой цикл изготовления обеспечивает высокую эффективность и безопасность препаратов растительного про- исхождения, а также высокое содержание и постоянство активных веществ, концентрация которых в дикорастущих растениях подвержена значительным колебаниям. Учитывая важное значение пролактина в регуляции различных процессов в организме, в т.ч. адаптационных возможностей и иммунитета, при коррекции гиперпролактинемии важным является достижение концентрации гормона в пределах фризиологических уровней. При этом следует избегать подавления его секреции до патологически низких показателей.

Исходя из полученных в наших предыдущих исследованиях данных о повышенном уровне стрессорного напряжения, психологической дезадаптации и проявлениях дисрегуляции высшей нервной системы у пациенток с ЛМ, а также о роли хронического стресса в возникновении гиперпролактинемии, патогенетически обоснованным является (в комплексе с препаратами специального экстракта Vitex agnus castus [BNO 1095 - Циклодинон, Мастодинон]), назначение лекарственных средств, способствующих купированию симптомов стрессового напряжения и способствующих повышению стрессовой адаптации [6, 29, 32].

При назначении препаратов, содержащих BNO 1095, на фоне психостабилизирующей и антифибротической терапии пациенткам с ЛМ при ДЗМЖ мы наблюдали значительную клиническую регрессию не только болевых симптомов в молочных железах и их нагрубания, но и боли внизу живота, характеризующей постэмболизационный синдром [32]. Позитивная динамика была подтверждена и сонографическими данными: отмечалось уменьшение диаметра больших кист и среднего количества мелких кист в молочных железах, а в некоторых случаях - и уменьшение ультразвуковой плотности их ткани. Среди пациенток данной группы с повышенной концентрацией пролактина в центральном кровотоке в 81,2\% случаев наблюдалась его нормализация до физиологических уровней. При этом ни в одном из случаев не отмечено падения уровня гормона до низких показателей (1-2 нг/мл), что иногда имеет место при назначении синтетических ингибиторов секреции пролактина. Следует также отметить хорошую переносимость терапии и отсутствие случаев отказа от приема препарата вследствие побочных эфрфректов.

\section{ВЫвОды}

Подытоживая вышеизложенное, можно сделать вывод, что общая и локальная гиперпролактинемия играет значительную роль в механизме развития как дисгормональных доброкачественных процессов в молочной железе, так и гиперпролиферативной патологии матки, в частности ЛМ. Подтверждение этого факта, с одной стороны, является очередной ступенью к пониманию патогенеза опухоли, с другой - открывает пути влияния на дисгормональные нарушения и профилактики дальнейшего роста и рецидивов ЛМ. Учитывая характеристики фитопрепарата Мастодинон, патогенетическое влияние и клинический опыт его применения, можно рекомендовать его назначение в комплексном лечении ЛМ и с целью профилактики ее роста. Безопасность, мягкое действие и возможность назначения широкому кругу пациенток ставят этот препарат в ряд средств первого выбора на начальном этапе комплексной терапии, а также профилактики рецидивов ЛМ после органосохраняющего ее лечения. 


\section{ЛИТЕРАТУРА}

\section{Bernichtein S.}

New concepts in prolactin biology / S. Bernichtein, Ph. Touraine, V.

Goffin // Journal of Endocrinology. - 2010. - Vol.206. - P. 1-11

\section{Egli M.}

Prolactin secretion patterns: basic mechanisms and clinical implications for reproduction / M. Egli, B. Leeners, T.H.C. Kruger // Reproduction. 2010. - Vol. 140. - P. 643-654.

\section{Clapp C., Thebault S., Qeziorski M.C.}

Peptide hormone regulation of angiogenesis, Physiol Rev 89. - 2009. P. 1177-1215.

\section{4. Архипкина Т.Л.}

Роль пролактина в фрормировании нарушений углеводного обмена у больных с синдромом поликистозных яичников / Т.Л. Архипкина, Л.П. Любимова, Е.И. Каленик // Проблеми ендокринної патології. 2010. - № 1. - С. 38-44.

\section{Grattan D.R.}

Prolactine: A pleirotropic neuroendsocrine hormone / D.R. Grattan, I.C. Kokay // Qournal of Neuroendocrinology. - 2008. -Vol. 20. - P. 752-763.

\section{6. Татарчук Т.Ф.}

Современные подходы к диагностике и лечению гиперпролактинемии / Т.Ф. Татарчук, С.В. Гуньков, О.А. Ефименко // Репродуктивная эндокринология. - 2012. - № 1(3). - С.44.

\section{Bole-Feysot $\mathrm{C}$.}

Prolactin and its receptor, actions, signal transduction pathways and phenotypes, observedin PRL receptor knockout mice // Endoc. Rev. 1998. - Vol. 19. - P. 225.

\section{Ben Jonathan $\mathbf{N}$.}

What can we learn from rodents about prolactin in humans? / Jonathan N., Ben C.R. Lapensee, E.W. Lapensee // Endocrine Reviews 29. - 2008. P. 1-41.

\section{Nowak R.A.}

Prolactin is an autocrine or paracrine growth factor for human myometrial and leiomyoma cells / Nowak R.A., Mora S., Diehl T. et al. // Gynecol Obstet Invest. - 1999. - Vol. 48. - P. 127-132.

\section{Bernichtein S.}

New concepts in prolactin biology / S. Bernichtein, P. Touraine, V. Goffin // Journal of Endocrinology. - 2010. - Vol.206. - P. 1-11

\section{Stattin $P$.}

Plasma prolactin and prostate cancer risk: a prospective study / P Stattin, S., Rinaldi, U.H. Stenman et al. // International Journal of Cancer. 2001. - Vol.92. - P. 463-465.

\section{Ginsburg $\mathrm{E}$.}

Prolactin synthesis and secretion by human breast cancer cells / E. Ginsburg, B.K. Vonderhaar // Cancer Research. - 1995. - Vol.55. P. 2591-2595.

\section{Levina V.}

Biological Significance of Prolactin in Gynecologic Cancers / V. Levina, B. Nolen, YunYun Su, A. Godwin, D. Fishman, J. Liu // Cancer Res. 2009. - 69: (12)

14. Goffin V., Struman I., Mainfroid V. et al. 1994 Evidence for a second receptor binding site on human prolactin / V.Goffin, I.Struman, V. Mainfroid et al. // Journal of Biological Chemistry. - 1994. -

P. 32598-32606.

\section{Baban R.S.}

Prolactin receptors in uterine leiomyomas. / R.S. Baban, S.T. Al-Zuheiri, Y.Y. Farid // Saudi Med J. - 2008. - Vol. 29, № 11. - P. 1593-1596.

\section{Gellersen B.}

Nonpituitary human prolactin gene transcription is independent of Pit-1 anddifferentially controlled in lymphocytes and in endometrial stroma / B. Gellersen, R. Kempf, R. Telgmann, G.E. Di Mattia // Molecular Endocrinology. - 1994. - Vol. 8. - P. 356-373.
17. Chapitis J.

Physicochemical characterization and functional activity of fibroid prolactin produced in cell culture / J. Chapitis, D.H. Riddick, L.M. Betz et al. // Am. J. Obstet. Gynecol. - 1988. - Vol. 158, № 4. - P. 846-853.

\section{Nowak R.A.}

Production of prolactin by smooth muscle cells cultured from human uterine fibroid tumors / R.A. Nowak, M.S. Rein, L.J. Heffen et al. //Clin. Endocrinol. Metab. - 1993. - Vol. 76, № 5. - P. 1308-1313.

\section{Daly D.C.}

Prolactin production from proliferative phase leiomyoma / D.C. Daly, C.A. Walters, J.C. Prior et al. // Am. J Obstet. Gynecol. - 1984 - - Vol. 148, № 8. P. 1059-1063.

\section{D. Dixon.}

Cell proliferation and apoptosis in human uterine leiomyomas and myometria / D. Dixon, G.P. Flake, A.B. Moore et al. // Virchows Arch. 2002. - Vol. 441, № 1. - P. 53-62.

\section{Chapitis J.}

Physicochemical characterization and functional activity of fibroid prolactin produced in cell culture / J. Chapitis, D.H. Riddick, L.M. Betz et al. // Am. J. Obstet. Gynecol. - 1988. - Vol. 158, № 4. - P. 846-853.

\section{Daly D.C.}

Prolactin production from proliferative phase leiomyoma / D.C. Daly, C.A. Walters, J.C. Prior et al. // Am. J Obstet. Gynecol. - 1984. - Vol. 148, № 8. P. 1059-1063.

\section{Nowak R.A.}

Prolactin Is an Autocrine or Paracrine Growth Factor for Human Myometrial and Leiomyoma Cells / Nowak R.A., Mora S., Diehl T. Rhoades A.R., Stewart E.A. // Gynecol Obstet Invest. - 1999. - Vol. 48. P.127-132

\section{4. Вихляева Е.M.}

Руководство по диагностике и лечению лейомиомы матки. - М.: МЕДпресс-инсоорм, 2004. - 400 с.

\section{Melli M.S.}

Comparison of the effect of gonadotropin-releasing hormone analog (Diphereline) and Cabergoline (Dostinex) treatment on uterine myoma regression / M.S. Melli, L. Farzadi, El. O. S. Madarek // Saudi Med J. 2007. -Vol. 28 (3). - P. 445-450

\section{Sabry $M$}

Innovative Oral Treatments of Uterine Leiomyoma / M. Sabry, A. Al-Hendy // Obstetrics and Gynecology International. - Volume 2012 .P.1-10.

\section{Sayyah-Melli M.}

Comparison of the effect of gonadotropin-releasing hormone agonist and dopamine receptor agonist on uterine myoma growth. Histologic, sonographic, and intra-operative changes / M. SayyahMelli, S. Tehrani-Gadim, A. Dastranj-Tabrizi et al. // Saudi Medical Journal. - 2009. - Vol. 30, № 8. - P. 1024-1033.

\section{8. Фахрутдинова Э.Х.}

Репродуктивное здоровье женщин после консервативной миомэктомии: Автореср. дис. канд. мед. наук. - М., 2004. - С. 20-27.

\section{9. Торчинов А.М.}

Исследование гормонального просриля у больных после гинекологических операций / А.М. Торчинов, М.М. Умаханова, Ю.В. Боклагова // Акушерство и гинекология - научнопрактический журнал. - 2012. - № 1. - С. 80-87.

30. Пиддубный М.И., Хасханова Л.Х., Духин А.О. и соавт. Отдаленные результаты восстановления репродуктивного здоровья женщин после консервативной миомэктомии // Вестник Российского университета дружбы народов. - М, 2002. - № 1. C. $125-128$.

\section{1. Бурдина И.И.}

Возможности фритотерапии в лечении доброкачественных заболеваний молочной железы // Репродуктивное здоровье женщины. - 2005. - № 2(22). - С. 131-133.

\section{2. Косей H.B.}

Фітотерапія в лікуванні дисгормональних доброякісних захворювань молочних залоз у жінок з лейоміомою матки // Репродуктивное здоровье женщины. - 2008. - № 4. - С. 171-173. 